USAD, Güz 2021; (15): 127-136

E-ISSN: 2548-0154

\title{
GARCİSTÂN BEYLERİ: ŞÂR AİLESİ
}

\section{GHARJISTAN AMIRS: DYNASTY OF SHAR}

İzetullah ZEKI *

$\ddot{O} z$

Şâr ailesi, XI. yüzyılda günümüzde Afgan Türkistan'ında bulunan Murgab Nehri kıyılarında yaşamıştır. Hanedan ilk başta Sâmânîlere bağhı yarı bağımsız bir Türk Beyliği olarak varlığını korumuştur. Ailenin kurucusu Şâr Reşid'dir. Kurucusunun künyesine nispetle hanedanın başına geçen tüm hükümdarlar Şâr olarak anılmıştır. Başta Şâr Reşid olmak üzere altı kişi hanedanın başına gelmiştir. Bunlar Şâr Ebu Nasr Muhammed b. Esed, Şâr Şah Ebu Muhammed b. Muhammed, Şâr Urdeşir, Şâr İbrahim $b$. Urdeşir ve Şâr Şah b. İbrahim'dir. Hanedan bir müddet Sâmânîlere bağhl isyancı Ebu Ali Simcûrî'nin saldırılarına maruz kalmıştır. Sebük Tegin'in devreye girmesiyle tekrar eski statüsünü kazanan Şâr ailesi, 389/999 yılında Şâr Ebu Nasr döneminde Gaznelilere bağlanmış, Garcistân sikkeleri Sultan Mahmud adına basılıp camilerinde adına hutbe okutulmuştur.

Bir müddet sonra Gazneli Mahmud, Hindistan'a gazaya gitmeye niyetlenmiştir. Şâr ailesinin de yanında yer almasını istemiştir. Ancak hanedanın başında bulunan Şâr Şah, türlü bahaneler ileri sürerek Gazneli Mahmud'un fetih hareketlerine katılmaktan imtina etmiştir. Hindistan gazasını daha ehemmiyetli gören Gazneli Mahmud, haritasımı çizdiği fetih hareketine devam etmiştir. Fakat Şâr ailesiyle hesaplaşmayı daha sonraya bırakmıştır. Kısa bir süre sonra gazadan dönen Gazneli Mahmud, güçlü bir ordu ile emirlerinden Emir Hâcib Altıntaş ve Arslan Câzib'i Garcistân üzerine göndermiştir. Gazneli ordusuna karşı savaşamayacağım anlayan Şâr Ebu Nasr, oğlu Şâr Şah'ı isyanından vaz geçirmeye çalıştıysa da başarılı olamamıştır. Savaştan sonra Gazne'ye getirilen Şâr ailesi Gazneli Mahmud'un ihsan ve ikramına mazhar olmuş, ihtiyaçları görülmüştür. Herat'ta

* Doç. Dr., , Burdur Mehmet Akif Ersoy Üniversitesi İlahiyat Fakültesi İslam Tarihi ve Sanatları Bölümü, Burdur/ Türkiye, izzetullahzeki@yahoo.com, https://orcid.org/0000-0001-6571-7377. 


\title{
128 | USAD İzzetullah ZEKI
}

Gaznelilerin gözetiminde tutulan Şâr Ebu Nasr, 407/1016 yllında vefat etmiştir. Bundan böyle Gaznelilerin topraklarına katılan Garcistân, ilerleyen tarihlerde Selçuklular ve Hârizmşahların egemenliğine girmiştir.

\author{
Anahtar Kelimeler
}

Garcistân, Şâr, Sâmânîler, Gazneliler, Şar Şah

\begin{abstract}
The Shar family lived on the banks of the Murgab River in present-day Afghan Turkestan in the 11th century. At first, the dynasty maintained its existence as a semi-independent Turkish Principality attached to the Samanids. The founder of the family is Shar Rashid. All the rulers who came to the head of the dynasty in relation to the identity of their founder were referred to as shar. Six people, especially Shar Rashid, became the head of the dynasty. These are Shar Abu Nasr Muhammad b. Asad, Shar Shah Abu Muhammad b. Muhammad, Shar Urdashir, Shar Ibrahim b. Uraeshir and Shar Shah b. Abraham. The dynasty was exposed to the attacks of Abu Ali Simjuri, a rebel loyal to the Samanids, for a while. The Shar family, which regained its former status with the intervention of Sabuk Tagin, was attached to the Ghaznavids during the reign of Shar Abu Nasr in 389/999, the Gharjistan coins were printed in the name of Sultan Mahmud and a sermon was delivered in their mosques.

After a while, Mahmud of Ghazni intended to go to India for Ghaza. He wanted the Shar family to be with him. However, Shar Shah, who was at the head of the dynasty, refrained from participating in the conquest movements of Mahmud of Ghazni by making various excuses. Ghaznavid Mahmud, who saw the Indian Ghaza as more important, continued the conquest movement that he had drawn. However, he left the reckoning with the Shar family for later. After a short while, Mahmud of Ghazni, who returned from the war, sent his amirs Amir Hâjib Altıntash and Arslan Jâzib against Garjistan with a strong army. Realizing that he could not fight against the Ghaznavid army, Shar Abu Nasr tried to dissuade his son Shar Shah from his rebellion, but he was unsuccessful. The Shar family, who was brought to Ghazni after the war, received the favors and favors of Mahmud of Ghazni, and their needs were met. Shar Abu Nasr, who was kept under the supervision of the Ghaznavids in Herat, died in 407/1016. From now on, Garjistan, who joined the lands of the Ghaznavids, came under the rule of the Seljuks and Hârizmşahlar in the following dates.
\end{abstract}

\section{Keywords}

Gharjistan, Shar, Samanids, Ghaznavids, Shar Shah 


\section{GİRIŞ}

Çalışmanın giriş kısmında Şâr hanedanının ait olduğu Horasan'ın coğrafi durumu hakkında kısa bir bilginin sunulması münasip görülmüştür. Asırlar boyunca ilim, kültür ve medeniyetin beşiği olan güneş ülkesi Horasan, 31/651 yılında ikinci İslam Halifesi Hz. Osman (ra) tarafından fethedilerek İslam Devleti'ne bağlanmıştır (Gerdîzî, 1949, s. 297; Hamevî, 1977, s. 350; Gubar, 2005, s. 80). Horasan, geniş bir coğrafyaya sahip olmasından dolayı araştırmacılar tarafından farklı tanımlamalar yapılmasına sebep olmuştur. Ulaştığımız bilgilere göre Horasan adından bahseden ilk tarihçi Ebü'l-Hasen Ahmed b. Yahyâ b. Câbir b. Dâvûd el-Belâzürî'dir (ö. 279/892-93). O, 255/858 yılında kaleme aldığ1 Fütûhü'lBüldan adlı eserinde Horasan'dan bahsetmiştir (Bilâzûrî, 1989, s. 562). Dönemin önemli tarihçilerinden Utbî ve Gerdîzî Nîşâbur'u Horasan ve sevk-i idarenin merkezi olarak aktarmışlardır (Gerdîzî, 1949, s. 297). Yakut el-Hemevî’ye göre Horasan sınırlarının başlangıcı Irak, Cevin ve Beyhak'tan başlamış, sonu Hindistan, Tohâristân, Gazne, Sicistân ve Kirman, Nîşâbur, Herat ve Merv'e kadar uzamıştır (Hamevî, 1939, s. 293).

Muasır Afgan tarihçisi Gulam Muhammed Gubar'ın aktardığına göre Horasan'ın genel ve özel olmak üzere iki tanımı bulunmaktadır. Onun özel tanımına göre Horasan, Afganistan'ın bir veya birkaç Kuzey ve Kuzey Batı bölgeleri için kullanılmıştır. Genel tanımına göre Horasan tüm Afganistan topraklarını kapsamaktadır (Gubar, 1947, s. 8). Yine ona göre Sâsânîler döneminde de Horasan kavramı kullanılıyordu. Fakat ondan önce Horasan adından bahsedilmemekteydi (Gubar, s. 2). Yine ona göre Enuşirvan-1 Âdil Afganistan bölgesini istila ettiğinde dört ana bölgeye ayırmıştı. Bu bölgeler Bâhtarîlerin Kuzey Doğusu, Nimrûz'un Güney Batısı, Horasan'ın Doğusu ve Doğu Bölgesi veya İranşehir olarak belirlenmişti (Gubar, s. 3). Doğu ve güneşin doğduğu yer anlamlarına gelen Horasan padişahlarından da Şark Padişahları olarak söz ediliyordu (Hamevî, 1939, s. 350; Gubar, s. 6).

Günümüze kadar Türkçede haklarında bağımsız bir çalışma yapılmayan ve bilinmeyen Şâr hanedanı Garcistân'da hüküm sürdüğü sırada Horasan'da Sâmânîlere bağlı Şâr hanedanı gibi birçok beylik bulunmaktaydı. Örneğin Gazne'de Sebüktegînîler, Cüzcân'da Ferîgûnîler, Gûr'da Gûrlûlar hüküm sürüyorlardı. Bu beyliklerin çoğu Müslüman Türklerden teşekkül etmekteydi. Ancak bazı çağdaş Fars araştırmacıları, zikri geçen beyliklerin kökenlerini herhangi bir delile dayandırmadan duygusallıkla bir nevi İran hanedanlıklarından göstermektedirler. Bu yanlış yorumların düzeltilmesi için Horasan beylikleri 
üzerine durulmuş, Ferîgûnîler ile Hârizmşâhlar iki bağımsız çalışma olarak yayınlanmıştır.

\section{Garcistân ve Hanedan Hakkında}

Dağlık bölge anlamına gelen ve Şâr ailesinin başkenti olan Garcistân, Herat'ın batısı, Gûr'un doğusu, Merv-i Rûd'un kuzeyi ve Gazne'nin güneyinde yer almaktadır (Hamevî, 1939, s. 193; Hudûdü'l-Âlem Mine'1-Meşrik İle'l-Mağrib, 1983, s. 93; Zeki, 2019, s. 251). Kralın dağları ve mülkü anlamlarına gelen Garcistân, Garçiştân, Garistân, Garsitân, Gharjistan, Ğarcestân ve Garci'ş-Şâr olarak da bilinmektedir (Dehhuda, 1994, s. 14676; Hüseyin, 2002, s. 37). Garcistân'da hüküm süren tüm hükümdarlar da Şâr olarak anılmaktadır (İbnü'1-Esîr, 1987, s. 4). Farsça bir kelime olan Şâr, (شار) şehir, aslan, ilbey, ilhan ve hükümdar anlamlarına gelmektedir (Gerdîzî, 2005, s. 467; Utbî, 1966, s. 323). Garcistân, özel kap1 ve surlara sahip bir bölge olup hükümdarın izni haricinde şehre kimse giremezdi. Garcistân halkı adil ve dürüst insanlar olarak bilinmekteydi. Garcistân'ın biri Afşin (Bişin) diğeri Sürmin (Şürmin) olmak üzere iki sulu ve elverişli önemli şehri bulunmaktaydı. Yöneticileri büyüklük açısından birbirine eşit olan bu iki şehir haricinde etrafı sağlam dağlarla sarılı Belkiyan (Burukan) adlı bir bölgede ikamet etmekteydiler (İbn Havkal, 1938, s. 443).

Hanedanın atası olarak bilinen Şâr Reşid ve ondan sonra iş başına gelen Esed hakkında fazla bilgiye rastlamamaktayız. Kaynaklarda geçen bilgi Şâr Hanedanının Esed ve oğlu Şâr Ebu Nasr Muhammed'in bölgenin İslam'la müşerref olmasından sonra Sâmânîlerin hizmetine girmiş olmaları, Ebu Nasr Muhammed'in Sâmânîler tarafından Garcistân'a vali olarak gönderilmiş olmasıdır (Yağlıkcızade, 1881, s. 122). Nakledildiğine göre Sâmânîler zayıflayınca Şâr Ebu Nasr Muhammed bağımsızlığını ilan ederek adil davranışlarda bulundu. Okuma yazmayı bilen Ebu Nasr Muhammed, ulemayı sevip sayar ve onlarla oturup kalkardı. Güzel davranışlarıyla halkın sevgisi ve desteğini kazanan Ebu Nasr Muhammed, uzun bir süreden sonra devlet işlerinden uzaklaşarak inzivaya çekildi, yerine oğlu Şâr Şah'1 getirdi. Kendisi ilim ve ibadetle meşgul oldu. Şâr Şah döneminde Simcûrîlerin, Garcistân'a saldırmaları Şâr Hanedanının Gaznelilerle tanışmaları, ardından bunlara bağlanmalarına sebep oldu (Utbî, 1966, s. 324).

Müslüman Ehl-i Sünnet Sâmânîler ve Gaznelilere bağlı olan Şâr ailesinin Müslüman olmaları kesin olup ancak etnik kökenleri hakkında fazla bilgi bulunamamaktadır. Bununla beraber muasır bazı araştırmaların da öne sürdükleri gibi bölgede aynı dönemde varlıklarını koruyan yerel Türk yönetimler Alp Teginîler, Ferîgûnîler ve Simcûrîler gibi Türk boylarından oldukları tahmin edilebilir. Nitekim modern Afganistan araştırmacılardan Nebizâde, 
Hârizmşahların kurucusunun Garcistânli bir Türk olduğu ve Şâr Hanedanının da günümüzde bölgede yaşayan Hazara Türklerinin ataları oldukları üzerine durmuştur (Nebizade, "Garcistân Ser Zemin-i Köhen ve İstibdadzade-i Afganistan"). Nitekim hâlihazırda Afganistanlı Hazaralar Garcistân adında özel bir üniversite kurarak bölgenin geçmişine de dikkat çekmektedirler.

\section{Şâr Hanedanının Gaznelilerle İlişkileri}

XI. yüzyıla kadar Horasan'1n Garcistân (غَشَشتان، غَرجستان) bölgesinde varlıklarını muhafaza eden Şâr Hanedanı hakkında kaynaklarda fazla bilgi bulunmaktadır (Zeki, 2020a, s. 15). Bunların iki hükümdar Şâr Ebu Nasr ile Şâr Şah hakkında en fazla bilgiyi aktaran şüphesiz dönemin iki tarihçisi Utbî ve Gerdîzî’dir. Utbî ve Gerdîzî hanedanın iki hükümdarı Ebu Nasr Muhammed b. Esed ve oğlu Muhammed Şah hakkında bilgi verir (Gerdîzî, 2005, s. 467). Utbî, Ebu Nasr'dan Garcistân'ın hükümdarı olarak bahseder (Utbî, 1966, s. 323; Celali, 2002, s. 117). Onun inzivaya çekilmesinin ardından oğlu Şâr Şah'ın yönetimin başına geçtiğini, devlet ve idareyi iyi bildiğini nakleder (Utbî, s. 323). Kaynak ve malzeme yetersizliğinden dolayı günümüze kadar hanedan hakkında bağımsız bir çalışmanın yapılmadığı görülmektedir. Utbî'nin naklettiğinden anlaşıldığına göre Şâr ailesi XI. yüzyılda Horasan'ı egemenliklerinde tutan Sâmânîlere bağlı bir yönetim olup daha sonra Gazneliler tarafından sona erdirilmişlerdir (Utbî, s. 323).

Sâmânîlere bağlı ve vefakâr bir hanedan olan Şâr ailesi, Gazneliler dışında mahalli yönetimlere bağlanmayı kabul etmemişlerdir. Nitekim Şâr Şah döneminde Sâmânîlere karşı isyan bayrağını kaldıran Simcûrî hanedanının lideri Ebu Ali Simcûrî, Garcistân topraklarını ele geçirmek için harekete geçer. Şâr ailesinin kendisine itaat etmelerini ister. Fakat Şâr ailesi Ebu Ali Simcûrî'nin isteğini reddederek sayelerinde gelişip büyüdükleri Sâmânîlere bağlı olduklarını dile getirirler. Sağlam kalelerine güvenerek karşı koyma gücüne sahip olduklarını ifade ederler. Bunun üzerine Ebu Ali Simcûrî, Ebü'l-Kasım Fakih'i önde gelen damlarıyla Garcistân'ı kuşatmaya gönderir. Dar ve geçilmesi zor dağ yolarından Garcistân üzerine gelen Simcûrî ordusu, çetin çarpışma ve kan dökmelerden sonra bölgeyi kontrolleri altına alırlar. Sel gibi kanların aktığı savaştan canlarını kurtaran iki Şâr (baba oğul) memleketlerinin uç noktalarında yer alan kalelerine sığınırlar. Garcistân eyaletini ele geçiren Simcûrîler, Şâr ailesinin hazinesi başta olmak üzere tüm mal varlıklarını yağmalarlar (Utbî, s. 324).

Ebu Ali Simcûrî önderliğinde Simcûrîlerin Garcistân'a girdikleri sırada Gazneliler Sebük Tegin liderliğinde Horasan'a hâkim olurlar. Bu gelişme üzerine Şâr ailesi, Sâmânîlere bağlı olan Sebük Tegin'den yardım talep ederler. Böylece Şâr ailesi Sebük Tegin'den gelen yardımla yeniden memleketlerine kavuşurlar (Utbî, 
s. 323). Şâr ailesi, Sebük Tegin'in bu iyiliğine karşı Horasan'daki seferlerine katılarak destek verirler (Zeki, 2020, s. 123). Sebük Tegin'in vefatından sonra tahta çıkan Gazneli Mahmud, başta Gazne olmak üzere Horasan üzerine hâkimiyetini yerleştirmeye çalışır. Bu çerçevede Cüzcân ve Sîstan'dan sonra Garcistân'daki Şâr ailesini de itaati altına almak üzere meşhur âlim ve tarihçi Abdilcebbâr Utbî’yi elçi olarak Garcistân'a gönderir. Utbî, Gazneli Mahmud'un elçisi sıfatıyla Şâr ailesi tarafından izzet ve ikramla karşılanır. 389/1012 yılında Garcistân sikke ve hutbelerinde Gazneli Mahmud'un adını görmekteyiz (Utbî, 1966, s. 324; Muhammed, 2002, s. 124; Muhammed, 1987, s. 19).

Şâr ailesi, Gaznelilere tabi olduktan sonra aralarında sıcak ilişkiler doğar. Bu çerçevede Gazneli Mahmud'un sarayına gelen Ebu Nasr'ın oğlu Şâr Şah onun lütuf ve inayetine mazhar olur. Gazneli Mahmud'un giydirdiği hilat ile tekrar Garcistân'a döner. Memleketine varan Şâr Şah, Gazneli Mahmud'un aleyhinde bazı eylem ve söylemlerde bulunsa da görmezden gelinir ve affedilir. Bir müddet sonra Gazneli Mahmud, Hindistan'a gazaya çıkmaya niyetlenir (Akkuş, 2019, s. 357). Bunun için her taraftan ordu toplar ve Şâr ailesinden de yaptığı anlaşmanın karşılığ1 olarak ordu göndermesini ister. Fakat daha önceden biriken itaatsizlikler üzerine biri daha yüklenir ve Şâr Şah, babasının uyarmasına rağmen Gazneli Mahmud'un ordu talebine olumsuz cevap vererek itaatsizliğini açığa vurur. Gaza meselesini Şâr ailesinin itaatsizliğinden daha acil ve ehemmiyetli gören Gazneli Mahmud, Hindistan seferine çıkar (Utbî, 1966, s. 328; Celali, 2002, s. 82).

Kısa bir süre sonra Hindistan seferinden muzaffer bir şekilde Gazne'ye dönen Sultan Mahmud, Şâr ailesinin itaatsizliğinin sorgulanması gerektiğini düşünür. Ordu emirlerinden Emir Hâcib Altıntaş ve Arslan Câzib'i Merv büyüklerinden Ebü'l-Hasan Meniî ile Garcistân üzerine gönderir. Kabalık Gazneli ordusunu gören Ebu Nasr, özür dileyerek aslen Garcistân Türklerinden olan Hâcib Altıntaş'a sığınma talebini iletir ve oğlunun isyankârlığından dolayı özür dileyerek Gazneli Mahmud'la aralarında şefaatçi olmasını ister. Bunun üzerine Hâcib Altıntaş, Ebu Nasr'1 saygın bir şekilde Herat'a getirir (Utbî, s. 328). Ebu Nasr Şâr, 406/1015 yılında Gazneli Mahmud'un gözetimindeyken Herat'ta vefat eder (Gerdîzî, 2005, s. 467).

Ancak babası Ebu Nasr'ın aksine oğlu Şâr Şah ise ülkenin sağlam kalelerine sığınarak tüm aile efradıyla hazine varlığını buraya nakleder. Bunun üzerine Hâcib Altıntaş ile Arslan Câzib bölgeyi kuşatırlar. Etrafı kuşatılan Şâr Şah, özür dileyerek teslim olmak zorunda kalır. Defalarca Gaznelilere itaatsizlik eden Şâr Şah'ın tüm mal varlığı yağmalanır. Esir edilen veziri Cehine-i Ahbar ise ufak bir tazip ve işkencenin ardından hanedanın tüm definelerinin yerini gösterir. Ardından 
Garcistân bölgesinin mali sorumluluğu Ebü'l-Hasan Meniî̀nin yetkisine birakılır. Şâr Şah'ın kendisi ise tutuklanarak Gazne' ye götürülür (Utbî, s. 329).

403/1012 yılında Gazne'ye götürülen Şâr Şah, zindana atılır ve tedip edilir (Gerdîzî, 2005, s. 260). Şâr Şah, hapisteyken Gazneli askerlerinden biri yanına gelerek sağlığının iyi olduğuna dair ailesine bir mektup yazmasını ister. Şâr Şah kısa bir süre bekledikten sonra kendi hanımını fahişelikle itham ederek tehditkâr bir mektup yazar. Mektubun içeriğini duyan hanımı ve ailesi evini terk ederek dağlara sığınır. Bu durum Gazneli Mahmud'a ulaşınca öfkelenir. "Hükümlü birisinin yanına kâtip bırakırsanız sonucu bu olur" diyerek tepkisini ortaya koyar. Şâr'ın kimsenin göremeyeceği ve kimse ile konuşamayacağı bir yerde tutulmasını emreder (Utbî, 1966, s. 329).

Zindanda yalnız başında canı sıkılan Şâr Şah, sultandan kendi işleriyle uğraşan bir gulamın yanına bırakılmasını ister. Şâr Şah'ın isteğine olumlu cevap veren Gazneli Mahmud, Herat'ta gözetimde tutulan babasının Gazne'ye getirilmesini emreder. Garcistân'da bulunan mülklerini satın alarak onlara gönderdiği bir miktar nakitle ihtiyaçlarını görmelerini ister (Utbî, s. 331). Şâr Şah'ın Babası Ebu Nasr, 406/1015 yilında Herat'ta vefat ederken kendisi ise Gazne'de zindanda vefat eder (Utbî, s. 331). Her ne kadar Şâr Şah sonrası Şâr Urdeşir, Şâr İbrahim b. Urdeşir ve Şâr Şah b. İbrahim'in isimler hanedan hükümdarlarının arasında geçiyorsa da Utbî ve Gerdîzî gibi dönemin tarihçileri bunlardan söz etmemektedir.

\section{SONUÇ}

Şâr ailesi XI. yüzyılda Horasan'ın Garcistân bölgesinde Sâmânîlere bağlı yarı bağımsız olarak kurulan, kısa bir süre sonra Gaznelilere bağlanan bir Türk Beyliğidir. Müslüman Ehli-i Sünnet oldukları kesin olan Şâr Hanedanı, bölgede varlığını koruyan diğer beylikler gibi Türk kökenlidirler. Şâr kelimesinin Farsça bir kelime olmasından dolayı İran kökenli oldukları iddia edilmişse de dönemin birçok devletinin dilinin Arapça ve Farsça olmasının devletlerin etnik kökeniyle ilgisi olmadığı açıtır. Yine onların Ehl-i Sünnet çizgisine bağlı önce Sâmânîler, ardından Gaznelilere bağlı kalmaları Pers kökenli olma varsayımını zayıflatmaktadir.

Başka bir önemli mesele ise hanedanın başına geçen hükümdarlardır. Her ne kadar altı kişinin Şâr Hanedanının başına geldiği nakledilmiş ise de Şâr Ebu Nasr ve Şâr Şah hariç baş ataları Şâr Reşid dâhil diğer aile fertleri hakkında bilgi bulunmamaktadır. Yegâne sağlam ve ayrıntılı bilgi Utbî’nin naklettiği, kendisinin de Gazneli Mahmud tarafından elçi olarak gittiği, ilk başta itaat edip, ardından isyan etmeleri üzerine bastırılarak nihayete erdirildikleri bilgisidir. 
Şâr Hanedanı hükümdarlarının liderlik vasıfları farklılık arz etmektedir. Araştırma sırasında ulaşılan bilgilere göre hanedanın kurulması bölgenin (Horasan'1n) İslamlaşmasına denk gelmektedir. Dolaysıyla hanedan liderlerinin hemen hepsi Müslüman Ehl-i Sünnet ve adaletli şahsiyetler olarak karşımıza çıkmaktadır. Başta Reşid, Esed ve Ebu Nasr olmak üzere hemen hepsinin dirayetli davranıp Sâmânîler sayesinde iktidara erişmiş ve zamanla özerkliklerini ilan etmişlerdir. Hanedan emirlerinden özellikle Ebu Nasr tecrübe ve dirayetiyle öne çıkmış, savaşın aksine Sâmânîler ve Gaznelilerle barış içinde yaşamayı tercih etmiştir. Fakat kendinden sonra yerine geçen genç yaştaki oğlu Şâr Şah'ın deneyimsiz ve aceleci bir kişiliğe sahip olduğu, bu kusurlarından dolayı Gazneli Mahmud'un öfkesiyle karşı karşıya kaldığı, buna binaen özerkliklerinin elden çıktığ1 görülmektedir.

\section{EXTENDED SUMMARY}

The Shar family is a Muslim and Ahl al-Sunnah dynasty. They are of Turkish origin, like other principalities that have preserved their existence in the region. Since the word Shar is a Persian word, it has been suggested that they are of Iranian origin. However, this idea is not based on conclusive evidence. As a matter of fact, their adherence to the Ahl as-Sunnah line, first the Samanids and then the Ghaznavids, weakens the assumption of Persian origin. The Shar family lived on the banks of the Murgab River in present-day Afghan Turkestan in the 11th century. At first, the dynasty maintained its existence as a semi-independent Turkish Principality attached to the Samanids. The founder of the family is Shâr Rashid. All the rulers who came to the head of the dynasty in relation to the identity of their founder were referred to as Shar. Six people, especially Shar Rashid, became the head of the dynasty. These are Shar Abu Nasr Muhammad b. Asad, Shar Shah Abu Muhammad b. Muhammad, Shar Urdashir, Shar İbrahim b. Uraeshir and Shar Shah b. Abraham. The dynasty was exposed to the attacks of Abu Ali Simjuri, a rebel loyal to the Samanids, for a while. The Shar family, which regained its former status with the intervention of Sabuk Tagin, was attached to the Ghaznavids during the reign of Shar Abu Nasr in 389/999, the Gharjistan coins were printed in the name of Sultan Mahmud and a sermon was delivered in their mosques.

After a while, Mahmud of Ghazni intended to go to India for Ghaza. He wanted the Shar family to be with him. However, Shar Shah, who was at the head of the dynasty, refrained from participating in the conquest movements of Mahmud of Ghazni by making various excuses. Ghaznavid Mahmud, who saw the Indian Ghaza as more important, continued the conquest movement that he had 
drawn. However, he left the reckoning with the Shar family for later. After a short while, Mahmud of Ghazni, who returned from the war, sent his amirs Amir Hâjib Altıntash and Arslan Jâzib against Garjistan with a strong army. Realizing that he could not fight against the Ghaznavid army, Shar Abu Nasr tried to dissuade his son Shar Shah from his rebellion, but he was unsuccessful. The Shar family, who was brought to Ghazni after the war, received the favors and favors of Mahmud of Ghazni, and their needs were met. Shar Abu Nasr, who was kept under the supervision of the Ghaznavids in Herat, died in 407/1016. From now on, Garjistan, who joined the lands of the Ghaznavids, came under the rule of the Seljuks and Kharizmshahyan in the following dates. 


\section{KAYNAKÇA}

Akkuş, M. (2019). Gazneli Mahmud'un mutasavvıflarla ilişkileri. Selçuk Üniversitesi Türkiyat Araştırmaları Dergisi, (45), 353-369.

Anonim. (1983). Hudûdü'l-âlem mine'l-maşrik ile'l-Mă̆rib. Tahran: Kitâbhâne-i Tahûrî.

Bilâzûrî, A. (1989). Fütûhü'l-büldan (C. IV). Tahran: İntişârât-1 Nukra.

Celali, N. (2002). Sergüzeşt-i Gazneviyân. Tahran: Ehl-i Kalem.

Dehhuda, A. E. (1994). Lûgatnâme (C. X). Tahran: Müessese-i İntişârât ve Çâp-1 Danişgah-1 Tahran.

Gerdîzî, E. A. (1949). Zeynü'l-ahbâr. Tahran: Çahâne-i Armağan.

Gerdîzî, E. A. (2005). Zeynü'l-ahbâr (târîh-i Gerdîzî). Tahran: Encümen-i Âsâr ve Mefâhir-i Ferhengi Yay.

Gubar G. M. (1947). Horasan. Kâbil: Neşriyât-1 Mecelle-i Aryana, Matbaa-1 Umumi-i Kâbil.

Gubar G. M. (2005). Afganistan der mesir-i tarih. Kâbil: Benigâh-i İntişarât-1 Meyvend.

Hamevî, E. A. (1939). Mucemü'l-buldân (C. 4). Beyrut: Dâr-1 Sadr.

Hamevî, E. A. (1977). Mucemü'l-buldân (C. 2). Beyrut. Dâr-1 Sadr.

Hüseyin, N. (2002). Sahtar-ı tabî̀ Hazaracat. Kâbil: İntişârât-1 Salsal.

İbn Havkal, E. (1938). Kitabü sûretü'l-arz. Beyrut: Dar-1 Sadr.

İbnü'l-Esîr (1987). el-kâmil fî́t-târîh (C.8). Beyrut: Dârü'1-Kitâbü'l-İlmiyye.

Muhammed, B. A. (1987). Rusûmü'l-Gazneviyyîn ve nazmuhumü'l-ictimaiyye. Kahire: Mektebetü'l- Encilü'l-Misriyya.

Muhammed, B. A. (2020). el-hayatü's-siyasiyye ve mazahirü'l-hadara fi'l-Irak ve'l-maşrikü'lİslamî: min evail-i karnü'r-rabî el-hicrî hatta zuhûrü's-Selacika. Kahire: Dârü'l-Âlem-i Arabi.

Utbî, E. A. (1966). Târîh-i yemînî. Tahran: Tahra Üniversitesi Yay.

Yağlıkçızade, A. R. (1881). Lûgât-ı târîhîyye ve coğrafiyye (C. 3-4). İstanbul: Mahmut Bek Matbaası.

Zeki, İ. (2019). Gazneli Mahmud'un din politikası. Konya: Çizgi Kitabevi.

Zeki, İ. (2020b). Horasan'da hâkimiyet mücadelesi (821-1005). Konya: Çizgi Kitabevi.

Zeki, İ. (2020a). İlk dönem Horasan valileri: Emeviler ve Abbasilerin Horasan politikası (651-821). Konya: Çizgi Kitabevi.

Nebizade, M. İ. Garcistân ser zemin-i Köhen ve istibdadzade-i Afganistan. http://www.ariaye.com/dari6/siasi/nabizadah9.html, Erişim Tarihi: 16.03.2021.

https://www.iranicaonline.org/articles/garcestan?fbclid=IwAR11LnCdIgiJrenKgB755ahrugCA4UoO8UkSdYQ3AEajCXiXFpsY1y5Kdw, Erişim Tarihi: 17.04.2021. 